\title{
Erratum to: 'What is in a Word?'-The Use and Background for Terms and Definitions in Additive Manufacturing
}

\author{
Klas Boivie
}

\section{Erratum to:}

Chapter "What is in a Word?'-The Use and Background for Terms and Definitions in Additive Manufacturing" in: E. Pei et al. (eds.), Additive Manufacturing-Developments in Training and Education, https://doi.org/10.1007/978-3319-76084-1_11

In the original version of the book, belated corrections from author for Chapter 'What is in a Word?'-The Use and Background for Terms and Definitions in Additive Manufacturing" have to be incorporated. The erratum chapter and the book have been updated with the changes https://doi.org/10.1007/978-3-31976084-1_11 